\title{
Barbara Dańska-Borsiak
}

\section{DETERMINANTY TFP WEDŁUG DZIAŁÓW PRZEMYSŁU W POLSCE. DYNAMICZNA ANALIZA PANELOWA ${ }^{\dagger}$}

\begin{abstract}
$\mathrm{Z}$ a ry s t r e ś c i. W artykule podjęto próbę oszacowania wartości TFP $\mathrm{w}$ działach sekcji $\mathrm{D}$ „przetwórstwo" na podstawie funkcji produkcji Cobba-Douglasa. Następnie wskazano czynników, wpływające na kształtowanie się tej zmiennej. Jako narzędzia analizy stosowano model $\mathrm{z}$ heteroskedastyczności grupową i model dynamiczny, szacowane na podstawie danych panelowych.

S ło w a k 1 u c z o w e: dynamiczny model panelowy, funkcja produkcji, łączna produktywność czynników produkcji (TFP), systemowy estymator GMM.
\end{abstract}

\section{WSTĘP}

Łączna produktywność czynników produkcji (TFP, ang. Total Factor Productivity) jest definiowana jako produkt, który może być wytworzony z jednostkowych nakładów czynników produkcji. Wzrost TFP jest sposobem oceny zmian efektywności procesu produkcyjnego, wynikających z postępu technicznego. Wartości tej zmiennej są nieobserwowalne i mogą być wyznaczone między innymi na podstawie modelu produkcji Solowa.

Zasadniczym celem referatu jest analiza czynników, wpływających na kształtowanie się TFP w działach sekcji D ,przetwórstwo przemysłowe” w Polsce. Jako narzędzie analizy zastosowano panelowe modele dynamiczne.

\section{METODOLOGIA}

Modele panelowe są szacowane na podstawie szczególnego rodzaju danych przekrojowo-czasowych, w których liczba obserwowanych obiektów $N$ prze-

\footnotetext{
† Praca naukowa finansowana ze środków na naukę w latach 2007-2009, jako projekt badawczy nr N111 093833.
} 
kracza, niekiedy znacznie, liczbę punktów w czasie $T$. Cechą charakterystyczną ich konstrukcji jest wyróżnienie efektu grupowego, stałego w czasie, specyficznego dla danego obiektu. Dynamiczny model panelowy ma postać:

$$
y_{i t}=\alpha_{0}+\gamma y_{i, t-1}+\mathbf{x}_{i t}^{T} \boldsymbol{\beta}+\left(\alpha_{i}+\varepsilon_{i t}\right),
$$

dla $i=1, \ldots, N, t=1, \ldots, T$. Efekt grupowy $\alpha_{i}$ może być traktowany jako losowy i wówczas jest składową składnika losowego, albo nielosowy i wówczas staje się wyrazem wolnym ${ }^{1}$. Bez względu na to, czy $\alpha_{i}$ są losowe czy nie, opóźniona zmienna objaśniana jest skorelowana ze (stałymi w czasie) efektami grupowymi. Z tego powodu metody stosowane do estymacji statycznych modeli panelowych nie mogą być stosowane do estymacji modelu (1), gdyż estymatory te byłyby niezgodne i obciążone. W literaturze proponuje się alternatywne metody estymacji panelowych modeli dynamicznych. Ich przegląd znaleźć można np. w Baltagi (2008), Hsiao (2003). Metody te bazują na Metodzie Zmiennych Instrumentalnych, Metodzie Największej Wiarygodności lub Uogólnionej Metodzie Momentów (GMM). Zaletą GMM jest między innymi możliwość uwzględnienia alternatywnych założeń odnośnie korelacji zmiennych objaśniających (elementów wektora $\mathbf{x}_{i t}$ modelu (1)) ze składnikiem losowym $\varepsilon_{i t}$. Zmienne $\mathbf{x}_{i t}$ można traktować jako:

- endogeniczne, to znaczy $\mathbf{x}_{i t}$ są skorelowane $\mathrm{z}$ wartością bieżącą $\varepsilon_{i t} \mathrm{i}$ wartościami opóźnionymi $\varepsilon_{i, t-s}$, ale nieskorelowane $\mathrm{z}$ wartościami przyszłymi $\varepsilon_{i, t+s}$,

- z góry ustalone (słabo egzogeniczne), to znaczy $\mathbf{x}_{i t}$ są skorelowane z wartością bieżącą $\varepsilon_{i t}$, ale skorelowane z wartościami opóźnionymi $\varepsilon_{i, t-s}$,

- ściśle egzogeniczne, to znaczy $\mathbf{x}_{i t}$ są skorelowane $\mathrm{z}$ wartością bieżącą $\varepsilon_{i t}$, wartościami opóźnionymi $\varepsilon_{i, t-s}$, i z wartościami przyszłymi $\varepsilon_{i, t+s}$.

Możliwy jest też oczywiście przypadek „mieszany”, gdy składowymi wektora $\mathbf{x}_{i t}$ są różne, wymienione powyżej typy zmiennych.

Do estymacji modelu kształtowania się łącznej produktywności czynników produkcji (TFP), prezentowanego w niniejszym referacie zastosowano dwie, jak się wydaje, obecnie najpopularniejsze metody: GMM pierwszych różnic (FDGMM) przedstawioną przez Arellano i Bonda (1991), oraz systemowa GMM (SGMM) Blundella i Bonda (1998). Poniżej przedstawiona jest zasadnicza idea tych dwóch metod.

Zastosowanie FDGMM wymaga przyjęcia złożenia, że składnik losowy $\varepsilon_{i t}$ w równaniu (1) nie wykazuje autokorelacji. W celu usunięcia efektów grupowych $\alpha_{i}$ oblicza się pierwsze różnice modelu (1). W tak powstałym modelu, postaci:

$$
y_{i t}-y_{i, t-1}=\gamma\left(y_{i, t-1}-y_{i, t-2}\right)+\left(\mathbf{x}_{i t}^{T}-\mathbf{x}_{i, t-1}^{T}\right) \boldsymbol{\beta}+\left(\varepsilon_{i t}-\varepsilon_{i, t-1}\right),
$$

\footnotetext{
${ }^{1}$ Można też wyodrębnić dodatkowo trzecią składową, stałą względem obiektów, zwaną efektem czasowym.
} 
zmienne objaśniające zastępuje się właściwymi instrumentami, którymi są opóźnione poziomy zmiennych $\mathrm{z}$ góry ustalonych i endogenicznych, oraz pierwsze różnice zmiennych egzogenicznych. Jedno i dwustopniowy estymator, uzyskany przy zastosowaniu GMM z wykorzystaniem wskazanych powyżej instrumentów zaproponowali Arellano i Bond (1991), nazywając go first differenced GMM (FDGMM). Opracowali oni również odporny estymator wariancji dla metody jednostopniowej ${ }^{2}$.

Estymatory FDGMM mogą być silnie obciążone w przypadku, kiedy opóźnione poziomy zmiennych są słabymi instrumentami dla zmiennych zróżnicowanych Sytuacja taka ma miejsce między innymi wtedy, gdy liczba obserwacji w czasie jest mała, ocena parametru autoregresyjnego zbliża się do 1, lub gdy stosunek wariancji efektu grupowego do wariancji właściwego składnika losowego jest zbyt duży.

Blundell i Bond (1998) zaproponowali tzw. systemowy estymator GMM (SGMM). Zasadnicza idea SGMM polega na oszacowaniu systemu równań: modelu (2) i modelu (1), a więc przyrostów i poziomów tego samego modelu. Dla równań na przyrostach postępowanie jest takie, jak w FDGMM. Dla równaniach na poziomach postępowanie jest analogiczne, a instrumentami dla z góry ustalonych i endogenicznych zmiennych objaśniających są opóźnione pierwsze różnice odpowiednich zmiennych. Instrumenty te są właściwe, przy założeniu, że $\varepsilon_{i t}$ nie wykazuje autokorelacji i że prawdziwe są warunki początkowe, postaci: $\mathrm{E}\left(\alpha_{i} \Delta y_{i 2}\right)=0$ dla $i=1, \ldots, N$.

Oceny jakości modelu oszacowanego FDGMM lub SGMM dokonać można na podstawie testu autokorelacji Arellano-Bonda, lub testu Sargana (por. Arellano, Bond, 1991). Hipoteza zerowa testu Arellano-Bonda głosi, że autokorelacja drugiego rzędu składnika losowego w modelu pierwszych różnic, postaci (2), nie występuje. Występowanie autokorelacji pierwszego rzędu w tym modelu jest zjawiskiem spodziewanym, gdyż jeśli $\varepsilon_{i t}$ są niezależne, to ich pierwsze różnice są skorelowane rzędu 1. Występowanie autokorelacji rzędu wyższego niż $1 \mathrm{w}$ modelu (2) oznaczałoby jednak, że warunki momentów są niespełnione, lub, inaczej, że instrumenty użyte podczas estymacji GMM nie są właściwe. Drugą możliwością jest zastosowanie testu Sargana. Bada on prawdziwość warunków ponad-identyfikujących, nie wykorzystanych w procesie estymacji. Hipoteza zerowa głosi, że wykorzystane instrumenty są właściwe w sensie ich nie skorelowania ze składnikami losowymi modelu pierwszych różnic (2).

Dodatkową możliwość sprawdzenia, czy oceny parametrów uzyskane na podstawie FDGMM lub SGMM są nieobciążone daje porównanie ich z ocenami wyznaczonymi na podstawie estymatora wewnątrzgrupowego (WG) i esty-

\footnotetext{
${ }^{2}$ Standardowy estymator wariancji dla metody dwustopniowej jest silnie obciążony w dół, co pokazali Arellano i Bond (1991). Odporny estymator dla metody dwustopniowej zaproponował dopiero Windmeijer (2005).
} 
matora KMNK modelu pooled ${ }^{3}$. Nickell (1981) wykazał, że estymator WG parametru autoregresyjnego $\gamma$ jest, przy ustalonym $T$, obciążony w dół, a estymator KMNK jest obciążony w górę (np. Hsiao, 2003). Wartość zgodnego estymatora parametru $\gamma$ powinna zawierać się zatem pomiędzy wartościami tych dwóch estymatorów.

\section{OSZACOWANIE ŁĄCZNEJ PRODUKTYWNOŚCI CZYNNIKÓW PRODUKCJI NA PODSTAWIE MODELU WYDAJNOŚCI}

Łączna produktywność czynników produkcji (TFP) jest zmienną nieobserwowalna. Definiowana jest ona jako produkt, który może być wytworzony z jednostkowych nakładów czynników produkcji. Wzrost TFP jest sposobem oceny zmian efektywności procesu produkcyjnego, wynikających z postępu technicznego. TFP może być wyznaczona na podstawie modelu produkcji Solowa. Dokładny sposób postępowania zależy od charakteru analizowanych obiektów i rodzaju próby. W poniższym badaniu wykorzystano metodę, zaproponowaną przez Tokarskiego (2008) do wyznaczenia wartości TFP według województw. Polega ona na wyznaczeniu wartości TFP charakterystycznych dla poszczególnych obiektów (w niniejszym badaniu - działów) na podstawie zależności:

$$
\ln \left(\frac{Y_{i t}}{L_{i t}}\right)=\ln A+g t+\alpha \ln \left(\frac{K_{i t}}{L_{i t}}\right),
$$

gdzie: $Y$ - wartość produkcji sprzedanej w mln. $\mathrm{z}^{4}, L$ - nakłady pracy (wyrażone w tys. pracujących), $K$ - nakłady kapitału rzeczowego (mierzone wartością środków trwałych brutto w mln. zł.), $A e^{g t}>0$ - łączna produktywność czynników produkcji (TFP), $g$ - stopa postępu technicznego w sensie Hicksa, $\alpha$ - elastyczność zmiennej $Y$ względem zmiennej $K$. Wartości zmiennych obserwowane są dla $i$-tego działu $(i=15, \ldots, 37)$ w roku $t(t=1, \ldots, 9)$. Dane statystyczne, wykorzystane w badaniu, pochodzą z Roczników Statystycznych Przemysłu z lat 1998-2006. Dotyczą one 22 działów sekcji D - „przetwórstwo”, oznaczonych w klasyfikacji PKD numerami 15-37.

Zależność (3) jest zlogarytmowaną funkcją wydajności pracy CobbaDouglasa, Wynika z niej, że wydajność $Y_{i t} / L_{i t}$ zależy od technicznego uzbrojenia pracy $K_{i t} / L_{i t}$, oraz od TFP, przy czym TFP (równe $A e^{g t}$ ) jest jednakowe dla wszystkich działów i lat. Ponieważ, założenie takie jest trudne do przyjęcia, do modelu (3) wprowadzono zmienne zero-jedynkowe, dla każdego działu (jest to

\footnotetext{
${ }^{3}$ Estymator wewnątrzgrupowy jest stosowany do szacowania modeli statycznych, w których efekty grupowe $\alpha_{i}$ są nielosowe (modeli FEM). Model pooled to model szacowany na podstawie danych panelowych, w którym jednak nie wyróżnia się efektów grupowych ani czasowych i zakłada się, że macierz wariancji-kowariancji składnika losowego jest sferyczna.

${ }^{4}$ Oszacowano również model, w którym za $Y$ przyjęto wartość dodaną brutto w mln. zł, ale wyniki były znacznie gorsze, dlatego nie są tu prezentowane.
} 
tzw. procedura dywersyfikacji stałej ${ }^{5}$ ). Ostateczny model, na podstawie którego estymowano wartości TFP w działach ma postać:

$$
\ln \left(\frac{Y_{i t}}{L_{i t}}\right)=\sum_{i=15}^{37} \beta_{i} d_{i}+g t+\alpha \ln \left(\frac{K_{i t}}{L_{i t}}\right)+\varepsilon_{i t},
$$

gdzie $d_{i}$ jest zmienną zero-jedynkowa, przyjmującą wartość 1 dla $i$-tego działu.

Do estymacji parametrów modelu (4) zastosowano uogólnioną metodę najmniejszych kwadratów (UMNK), gdyż ze względu na duże zróżnicowanie wydajności i technicznego uzbrojenia pracy między działami założono występowanie heteroskedastyczności grupowej. Uzyskane wyniki, prezentowane w tabeli 1, wydają się zadowalające. Oszacowana stopa postępu technicznego w sensie Hicksa wynosi ok. 4\%, a elastyczność wydajności pracy względem technicznego uzbrojenia pracy jest równa 0,25 . Ponadto wszystkie zmienne są statystycznie istotne, a bardzo dobre dopasowanie modelu, mierzone współczynnikiem determinacji pozwala uznać, że wartości TFP, które zostaną wyznaczone na podstawie modelu (4) będą wiarygodne.

Tabela 1. Wyniki estymacji modelu wydajności postaci (4)

\begin{tabular}{|c|c|c|c|c|c|}
\hline Zmienna & $\begin{array}{c}\text { Ocena } \\
\text { parametru }\end{array}$ & $\begin{array}{l}\text { Istotność } \\
\text { zmiennej } \\
(p-\text {-value })\end{array}$ & Zmienna & $\begin{array}{c}\text { Ocena } \\
\text { parametru }\end{array}$ & $\begin{array}{l}\text { Istotność } \\
\text { zmiennej } \\
\text { (p-value) }\end{array}$ \\
\hline $\ln (K / L)$ & 0,248929 & 0,000 & $d 25$ & 3,675495 & 0,000 \\
\hline$t$ & 0,042265 & 0,000 & $d 26$ & 3,430858 & 0,000 \\
\hline$d 15$ & 3,782607 & 0,000 & $d 27$ & 3,82395 & 0,000 \\
\hline$d 16$ & 4,243143 & 0,000 & $d 29$ & 3,403139 & 0,000 \\
\hline$d 17$ & 3,171489 & 0,000 & $d 28$ & 3,547692 & 0,000 \\
\hline$d 18$ & 2,712089 & 0,000 & $d 30$ & 4,381864 & 0,000 \\
\hline$d 19$ & 2,980698 & 0,000 & $d 31$ & 3,671108 & 0,000 \\
\hline$d 20$ & 3,370759 & 0,000 & $d 32$ & 4,277701 & 0,000 \\
\hline$d 21$ & 3,854455 & 0,000 & $d 33$ & 3,417207 & 0,000 \\
\hline$d 22$ & 3,736069 & 0,000 & $d 34$ & 4,242604 & 0,000 \\
\hline$d 23$ & 4,679551 & 0,000 & $d 35$ & 3,444552 & 0,000 \\
\hline$d 24$ & 3,884442 & 0,000 & $d 36$ & 3,407981 & 0,000 \\
\hline & & & $d 37$ & 3,631315 & 0,000 \\
\hline \multicolumn{6}{|c|}{$R^{2}=0,976$} \\
\hline
\end{tabular}

Źródło: obliczenia własne.

Na podstawie wyników estymacji modelu (4) oszacowano następnie wartości TFP w dziale $i \mathrm{w}$ roku $t$ według wzoru:

$$
T F P_{i t}=\frac{\left(Y_{i t} / L_{i t}\right)}{\left(K_{i t} / L_{i t}\right)^{0,248929}},
$$

\footnotetext{
${ }^{5}$ Por. Pindyck, Rubinfeld (1991).
} 
gdzie wartość wykładnika w mianowniku jest oceną parametru $\alpha$ modelu (4).

Zróżnicowanie łącznej produktywności czynników produkcji według działów przedstawione jest na wykresie 1. Przedstawione są tam przeciętne wartości TFP z lat 1998-2006 w poszczególnych działach. Ponieważ wartości tej cechy są niemianowane, przyjęto, że przeciętne TFP dla działu 23 „koks, ropa naftowa", w którym poziom tej zmiennej jest najwyższy, równy jest 100 .

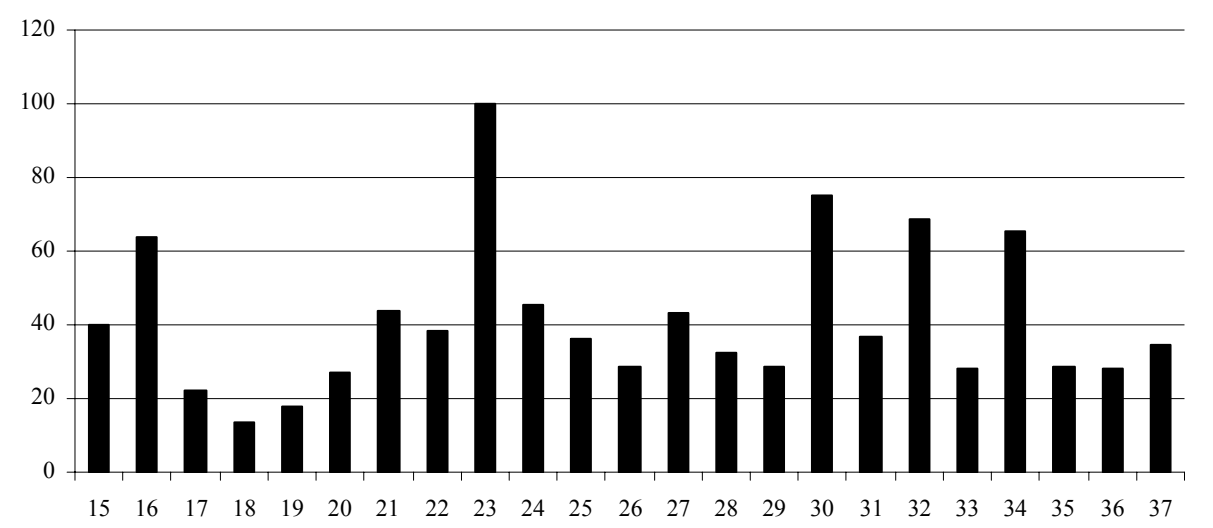

Wykres 1. Zróżnicowanie TFP według działów w latach 1998-2006 (dział $23=100)$

Źródło: opracowanie własne.

Na podstawie wykresu 1 stwierdzić można, że wysokimi wartościami TFP (powyżej $60 \mathrm{w}$ stosunku do działu 23) charakteryzują się działy: 30 „maszyny biurowe i komputery”, 32 ,sprzęt i aparatura RTV”, 34 ,pojazdy mechaniczne”, 16 „,wyroby tytoniowe”. Szczególnie niskie wartości TFP, nieprzekraczające 25, stwierdzono zaś dla działów: 18 „odzież i futrzarstwo”, 19 „skóra i wyroby”, 17 „tkaniny”. Dodatkowo obliczono współczynnik korelacji między roczną stopą wzrostu TFP a poziomem wartości tej cechy w działach (por. Tokarski (2008)). Współczynnik ten jest ujemny, ale jego wartość wynosi zaledwie -0.049. Jest to wartość zbyt niska by można było jednoznacznie stwierdzić występowania $\mathrm{w}$ okresie próby zjawiska konwergencji łącznej produktywności czynników produkcji na poziomie działów.

\section{MODEL KSZTAŁTOWANIA SIĘ ŁĄCZNEJ PRODUKTYWNOŚCI CZYNNIKÓW PRODUKCJI (TFP)}

Po oszacowaniu wartości TFP $\mathrm{w}$ działach podjęto próbę skonstruowania i oszacowania modelu ekonometrycznego, opisującego kształtowanie się tej zmiennej według działów. W związku z niedostępnością części danych, dotyczących działalności badawczo-rozwojowej (brak danych o nakładach i zatrudnieniu dla działów 16, 18, 19, 21, 37) oraz danych o imporcie i eksporcie dla wszystkich działów w latach 1998-1999, zdecydowano się zawęzić próbę. Analiza kształ- 
towania się TFP przeprowadzona została na podstawie danych dla 18 działów $(i=15,17,20,22, \ldots, 36) \mathrm{z}$ lat 2000-2006.

Zmienną objaśnianą estymowanych modeli jest łączna produktywność czynników produkcji wyznaczona według wzoru (5). Na podstawie opracowań o charakterze teoretycznym i empirycznym, znanych z literatury światowej ${ }^{6}$, wytypowano czynniki, mogące wpływać na poziom TFP. Są to: kapitał ludzki, kapitał fizyczny, nakłady na działalność badawczo-rozwojową (BiR), stosunek eksportu do produkcji i stosunek importu do produkcji.

Oszacowanych zostało kilkanaście modeli, w których zmiennymi objaśniającymi były alternatywne miary wymienionych powyżej czynników, mogących mieć wpływ na produktywność. Kapitał ludzki aproksymowano jako stosunek liczby zatrudnionych na stanowiskach nierobotniczych do liczby zatrudnionych ogółem $(l z n / l z)$, lub jako stosunek liczby zatrudnionych w działalności BiR do liczby pracujących ogółem $(z b r l p)^{7}$. Miarą kapitału fizycznego była wartość środków trwałych brutto na jedna przepracowaną godzinę (stbh) wyrażona w zł/godz. Zmiennymi, odzwierciedlającymi wpływ transferu technologii, dokonującego się poprzez handel międzynarodowy, były stosunek wartości importu do wartości produkcji sprzedanej (imps) i stosunek wartości eksportu do wartości produkcji sprzedanej (ekps). Miarą wpływu działalności badawczorozwojowej na TFP był stosunek nakładów na BiR do nakładów inwestycyjnych (brinw). Wymienione powyżej zmienne wprowadzane były do modelu albo jako wartości bieżące, albo opóźnione o 1 lub 2 okresy. Ostateczna postać modelu, który charakteryzował się najlepszymi własnościami merytoryczno-statystycznymi jest następująca:

$$
\begin{aligned}
\ln \left(T F P_{i t}\right)= & \alpha_{0}+\gamma \ln \left(T F P_{i, t-1}\right)+\beta_{1} \ln \left(\text { zbrlp }_{i t}\right)+\beta_{2} \ln \left(\text { brinw }_{i, t-2}\right)+ \\
& +\beta_{3} \ln \left(s t b h_{i t}\right)+\beta_{4} \ln \left(\text { imps }_{i t}\right)+\varepsilon_{i t}
\end{aligned} .
$$

Do estymacji modelu (6) stosowane były jednostopniowa FDGMM i SGMM. Zmienne objaśniające (wszystkie lub część z nich) traktowane były alternatywnie jako zmienne ściśle egzogeniczne, słabo egzogeniczne lub endogeniczne. W wyniku wielu prób uznano ostatecznie, że zmiennymi nie egzogenicznymi są zmienne opisujące działalność BiR: brinw (nakłady) i zbrlp (zatrudnienie). W tabeli 2 przedstawione są wybrane wyniki estymacji modelu (6) uzyskane przy zastosowaniu wspomnianych powyżej metod. Oznaczenia „endo”, „pre” i „egzo” przy nazwach metod SGMM i FDGMM określają jak traktowane były zmienne brinw i zbrlp: endogenicznie, słabo egzogenicznie lub ściśle egzogenicznie.

\footnotetext{
${ }^{6}$ Por. Cameron (2006), Griffith, Redding, Van Reen (2003), Coe, Helpman (1995), Acharya, Keller (2007).

${ }^{7}$ Niedostępne są dane o liczbie pracujących w działach według wykształcenia, zatem konstrukcja innych miar była niemożliwa.
} 
Tabela 2. Wyniki estymacji modeli kształtowania się TFP

\begin{tabular}{|c|c|c|c|c|}
\hline \multirow{3}{*}{$\begin{array}{c}\text { Zmienna } \\
\text { objaśniająca / Test } \\
\text { statystyczny }\end{array}$} & \multicolumn{4}{|c|}{ Metoda estymacji } \\
\hline & 1 & 2 & 3 & 4 \\
\hline & SGMM endo & SGMM pred & SGMM egzo & FDGMM endo \\
\hline$t f p_{i . t-1}$ & $0,793253^{\star * *}$ & $0,857312^{\star \star *}$ & $0,87122^{\star * *}$ & $0,798187^{* * *}$ \\
\hline zbrlpit & $0,11515^{\star \star \star}$ & 0,03595 & 0,0551 & $0,09582^{\star * \star}$ \\
\hline brinwit $_{\text {it }}$ & $0,098499^{* * *}$ & $0,031823^{*}$ & 0,046598 & $0,055108^{* * *}$ \\
\hline brinwi.t-2 $_{\text {- }}$ & $0,019789^{*}$ & 0,003219 & 0,007536 & 0,004063 \\
\hline impsit & $0,11743^{*}$ & $0,126875^{* * *}$ & $-0,04389$ & $-0,07901^{*}$ \\
\hline$s t b h_{i t}$ & $0,147437^{* * *}$ & 0,008911 & 0,063616 & $0,036018^{*}$ \\
\hline Const & 0,249468 & $0,702453^{*}$ & 0,173642 & 0,33449 \\
\hline$m_{1}$ & $-2,8453$ & $-2,7748$ & $-3,0989$ & $-3,2012$ \\
\hline [p-value] & {$[0,0024]$} & {$[0,0055]$} & {$[0,0019]$} & {$[0,0014]$} \\
\hline$m_{2}$ & $-0,51259$ & $-1,2058$ & & $-0,39931$ \\
\hline [p-value] & {$[0,6082]$} & {$[0,2279$} & $-0,50555[0,6132]$ & {$[0,6897]$} \\
\hline
\end{tabular}

symbol *** przy ocenie parametru oznacza, że wartość $p$ dla testu t-Studenta $p<0,05$; symbol * oznacza $p \leq 0,1$; pozostałych zmiennych nie można uznać za istotne. Błędy szacunku parametrów wyznaczane były na podstawie odpornych estymatorów macierzy wariancji-kowariancji składnika losowego;

$m_{1}$ i $m_{2}$ oznaczają wartości empiryczne testu autokorelacji Arellano-Bonda, odpowiednio AR(1) i AR(2); w nawiasach kwadratowych - wartości $p$ dla $H_{0}$ : autokorelacja pierwszego (drugiego) rzędu nie występuje. Test Sargana nie był stosowany, gdyż w przypadku wyznaczenia odpornych estymatorów błędów szacunku rozkład empiryczny nie jest znany.

Źródło: obliczenia własne.

Test autokorelacji Arellano-Bonda, którego wyniki są prezentowane w tabeli 2 rozstrzyga jednoznacznie, że warunki momentów wykorzystane w procesie estymacji są poprawne. Dotyczy to wszystkich wariantów GMM, prezentowanych w kolumnach 1-4 tabeli 2. Wartości empiryczne statystyk $m_{1}$ i $m_{2}$ oznaczają, że w modelu pierwszych różnic występuje autokorelacja pierwszego rzędu, natomiast brak jest autokorelacji rzędu 2. Zatem instrumenty użyte podczas estymacji GMM są właściwe.

Porównanie wyników zawartych w kolumnach 1-4 tabeli 2 wskazuje jednoznacznie, że najlepszą metodą estymacji modelu (6) jest SGMM z założeniem endogeniczności zmiennych brinw i zbrlp (kolumna 1). Dodatkowe badania wykazały, że ocena parametru autoregresyjnego $(0,79)$ zawiera się pomiędzy oceną WG $(0,7)$ a oceną $\operatorname{KMNK}(0,95)$, co świadczy o zgodności estymatora SGMM. Najsilniejszy wpływ na wzrost TFP wywiera wzrost kapitału fizycznego (elastyczność 0,15\%) i kapitał ludzki (elastyczność 0,12\%). Równie znaczący jest wpływ transferu technologii na wzrost TFP. Elastyczność zmiennej imps względem TFP wynosi $0,12 \%$. Odpowiednie mnożniki długookresowe wynoszą $0,713,0,557$ i 0,568 . Wysoka wartość oceny parametru autoregresyjnego modelu (6) świadczy o stabilności w czasie łącznej produktywności czynników produkcji charakterystycznej dla działów. 


\section{ZAKOŃCZENIE}

W prezentowanym badaniu dokonano oszacowania wartości łącznej produktywności czynników produkcji w działach sekcji „przetwórstwo przemysłowe", a następnie wskazano czynniki, wpływające na kształtowanie się TFP. Jako narzędzia analizy stosowano model $\mathrm{z}$ heteroskedastyczności grupową i model dynamiczny, szacowane na podstawie danych panelowych.

Uzyskane wyniki wskazują na duże zróżnicowanie TFP między działami, przy czym nie stwierdzono tendencji do wyrównywania się tych różnic. Wykazano, że istotny wpływ na kształtowanie się TFP wywiera kapitał fizyczny, kapitał ludzki, transfer technologii i działalność badawczo-rozwojowa.

\section{LITERATURA}

Acharya R. C., Keller W. (2007), Technology Transfer through Imports, NBERWorking Paper, 13086.

Arellano M., Bond S. (1991), Some Tests of Specification for Panel Data: Monte Carlo Evidence and an Application to Employment Equations, „Review of Economic Studies", 58, 277-297.

Ascari G., Di Cosmo V. (2004), Determinants of Total Factor Productivity in the Italian Regions, University of Pavia, Department of Economics, Working Paper, \# 170 (12-04), http://129.3.20.41/eps/mac/papers/0511/0511009.pdf (8.03.2009).

Baltagi, B. H. (2008), Econometric Analysis of Panel Data, Wiley\&Sons, Chichester

Blundell R., Bond S. (1998), Initial Conditions and Moment Restrictions in Dynamic Panel Data Models, „Journal of Econometrics”, 87(1), 115-143.

Cameron, G. (2006), Openness, $R \& D$, and Growth at the Industry Level, str. 137-158, w: Finley, L. A. (ed) Perspectives on Economic Growth, Nova Publishers: Hauppauge NY.

Coe D., Helpman E. (1995), International R\&D Spillovers, „European Economic Review", 39, 859-887.

Griffith R., Redding S., Van Reen J. (2003), $R \& D$ and Absorptive Capacity: Theory and Empirical Evidence, ,Scandinavian Journal of Economics”, 105, 99-118.

Hsiao, C. (2003), Analysis of Panel Data, 2nd edn., Cambridge University Press, Cambridge.

Nickell S. (1981), Biases in Dynamic Models with Fixed Effects, „Econometrica”, 49, $1417-1426$.

Pindyck R.S., Rubinfeld D.L. (1991), Econometric Models and Economic Forecasts, McGraw-Hills, New York.

Tokarski, T. (2008), Oszacowanie regionalnych funkcji produkcji, „Wiadomości Statystyczne", 10, 38-53.

Windmeijer, F. (2005), A Finite Sample Correction for the Variance of Linear Efficient Two-Step GMM Estimators, „Journal of Econometrics”, 126(1), 25-51. 


\title{
TFP DETERMINANTS IN POLISH MANUFACTURING. DYNAMIC PANEL ANALYSIS
}

\begin{abstract}
A b s t r a c t. The main goal of the paper is to determine the factors, that influence total factor productivity in the sectors of manufacturing in Poland. TFP is an unobservable variable, so as a first step its values has been estimated on the ground of the Cobb-Douglas production function. Dynamic panel data model and groupwise heteroscedastic panel data model were the basic tools of the analysis.
\end{abstract}

K e y w o r d s: dynamic panel data model, total factor productivity (TFP), production function, System GMM estimation. 